more common psychiatric conditions, namely anxiety, sleep disturbance, depression, schizophrenia and mania. This it does very well indeed, with fully documented discussions on the pharmacological actions and kinetics of the drugs involved. However, like most American books, it does not mention some drugs now used widely in Britain, e.g. mianserin and nomifensin. But clinical pharmacology is more than therapeutics, and it is a pity that the monograph does not contain some general introduction to basic human psychopharmacology and drug kinetics from which the particular problems met in anxiety, depression and so on, could develop. Without such an introduction some students of psychiatry may well find that the book assumes a certain level of knowledge on these subjects that they do not possess. Nevertheless, Professor Hollister is a world authority in the treatment of psychiatric disorders, and this book provides an opportunity to share his long experience in the practical management of these conditions.

Although quite expensive, it will undoubtedly prove of great interest to British psychiatrists.

\section{A Colour Atlas of Periodontology}

By J. D. Strahan and I. M. Waite. Pp. 144, illustrated. Wolfe Medical Publications, London, 1978. $£ 12.00$.

This volume of the series of colour atlases on oral topics is worth-while, setting out clearly the basics of periodontology.

The first chapter on the anatomy of the periodontium is an excellent way to start a book, reminding the reader of the healthy mouth and the structures involved in the periodontium and the effects of variations on them.

The definition of gingivitis in Chapter 2/31 may be a little confusing, because clinically it is possible to see an inflammatory reaction in the gingival margin without pocket formation (the gingival crevice being of the depth for health, i.e. $0.5 \mathrm{~mm}$ ) although microscopically there is oedema.

A photograph to accompany the section (67) of a papilloma would be welcome for clarity. In the same chapter (section 72), the warning regarding tetracycline in children is clearly set out; the regime of care for them is not mentioned, however, when it is essential that some help be given to the mother in dealing with the unhappy child with acute herpetic stomatitis. In the same section it should be pointed out that the recurrent episodes of herpes labialis can lead to herpetic whitlows if touched and that unaffected persons can be infected if kissed on the lips and, more rarely, the genitalia, the lesions on the latter are usually herpes hominis type II rather than the type I of herpes labialis.

In Chapter 8, on the control of dental plaque (104-110), the fact that there are 2 types of floss, waxed and non-waxed, should be made clear, and the type to use perhaps suggested.

Chapter 9 on scaling and polishing is one of a clarity most welcome and should be a must for all those learning and practising gingival rehabilitation. Unfortunately, the Blake Gingivectomy knives (151/152) are no longer commercially available which is a great pity because they are ideal instruments in gingivectomies.

Chapter 17 on fraenectomy continues with the clarity, which is a characteristic of the atlas, but I would suggest that fraenoplasty should be applied to the procedure except when applied in 219-221, where fraenectomy is the correct term.

The caption statement in Chapter 17 (254) is liable to be misconstrued in that it would appear to suggest that all orthodontic work is cosmetic. The same sentence does state that there is an increase in gingivitis during orthodontic therapy, and one should go further and state that the palatal mucosa may also be affected when wearing removable appliances as mentioned in Chapter 2 (38).

In Chapter 18 on occlusal adjustment, a mention of orthodontic movements should be considered in the next edition, because these may solve the occlusal problem.
The appendices are clear although the reviewer's choice would be that they were placed at the end of the appropriate chapters through the Atlas.

The points are puzzling, firstly, the E6 pliers in the instrumentation, presumably to break scalpel blades for the Blake knives and secondly, the statement regarding the anatomy of bone defects where the word 'coronal' is used which the reviewer thinks should be 'apical'.

In conclusion, this is an excellent book and should be in every practitioner's library'

Cunningham's Manual of Practical Anatomy, Volume 2. Thorax and Abdomen (14th Edition)

By G. J. Romanes, CBE, BA, PhD, MB, ChB, FRCS.Ed., FRSE. Pp. 232, soft cover, illustrated. Oxford: Oxford University Press, 1977. $£ 3.25$.

As in Volume 1, the text has been reorganized and abbreviated in an attempt to simplify the task of the students, while increasing their understanding of the complexities of the subject. References to function have been increased, as have illustrations from and applications to clinical practice. This should help to make students aware of the value and importance of the subject in the medical curriculum as well as providing added interest and incentive.

Brief descriptions of the main features of bones have been introduced with accompanying illustrations in the appropriate places in the text and in addition the illustrations of the bones have been gathered together for easy reference in atlas form at the end of the book. Also, at the end of the book, there are 2 very helpful tables. One gives the approximate levels of the structures in the trunk, and the other groups together the actions of the trunk musculature. Some 25 news illustrations have been provided including some explanatorye diagrams illustrating complex structures and relevant functional and developmental processes.

The surface anatomy sections have been extended to en sure that all structures visible or palpable can be identified. All the dissection necessary for the understanding of the functions of a particular system or region has been brought together so avoiding fractionation of information. In this way, it has been possible to deal with the functions of muscles and of joints in an integrated fashion, and to give a general account of the distribution of the various arteries and their anastomoses without going into the detailed course of each.

In rewriting the text the author has aimed at making the manual adequate in itself as a textbook of gross anatomy, whilst still retaining its usefulness as a dissecting manual for those schools where dissection is undertaken. It is arguable whether such a dual aim is attainable: for most courses of anatomy, the use of these manuals will need to be supplemented by reference to a systematic textbook, and the use of an atlas to supplement the illustrations will be at least desirable. The old type of Cunningham's dissecting manual is no longer appropriate for the current curtailed dissecting programmes, but with the new format and text something has been lost in terms of effectiveness as a guide to practical work in the dissecting room. That said, the author is to be congratulated on a distinguished effort to bring up to date this renowned guide to dissection. It is still very good value.

\section{Diagnosis and Treatment of Functional Infertility}

By B. Lumenfield and V. Insler with M. Glezerman. Pp. 202, illustrated. Berlin: Grosse, 1978. Price not given.

Books like this appeal to 2 classes or reader: the young graduate preparing for a higher examination, and the experienced gynaecologist who wishes to keep up to date. This book serves both purposes to some extent but does not fill the needs of either group completely. There are excellent, closely referenced, accounts of the interrelationships between 